\title{
Personalised External Aortic Root Support - how to implant it?
}

\author{
Petr Nemec ${ }^{1}$, Miroslav Kolarik ${ }^{2}$, and Petr Fila ${ }^{1}$ \\ ${ }^{1}$ Centre of Cardiovascular Surgery and Transplantation \\ ${ }^{2}$ Centre of Cardiovascular Surgery and Transplantation, Brno, CZ
}

March 14, 2021

\begin{abstract}
Personalized External Aortic Root support (PEARS) is an evolving method of treatment for patients with dilated aortic root or ascending aorta. The treatment is adopted in still more centres. For the sake of the safety of the procedure a standardized surgical technique is necessary. The authors describe surgical technique of the implantation that is derived from their extensive experience.
\end{abstract}

\section{Hosted file}

Personalised External Aortic Root Support -- how to implant it.pdf available at https: //authorea.com/users/401502/articles/513573-personalised-external-aortic-root-supporthow-to-implant-it 